\title{
Effect of dietary conjugated linoleic acid in combination with monounsaturated fatty acids on the composition and quality traits of cooked loin
}

\author{
Diana Martin, Teresa Antequera, Elena Muriel, Trinidad Perez-Palacios, Jorge Ruiz* \\ Tecnologia de Alimentos, Facultad de Veterinaria, Universidad de Extremadura, Avda. Universidad s/n, 10071 Caceres, Spain
}

\section{A R T I C L E I N F O}

\section{Article history:}

Received 27 October 2008

Received in revised form 5 May 2010

Accepted 16 June 2010

Available online $\mathrm{xxxx}$

\section{Keywords:}

Conjugated linoleic acid

Monounsaturated fatty acids

Cooked pork

Lipid oxidation

Volatile compounds

\begin{abstract}
A B S T R A C T
Three levels $(0 \%, 1 \%$ and $2 \%)$ of a conjugated linoleic acid oil (CLA) were combined with two levels of monounsaturated fatty acids (MUFA) (low - 19\% average and high - 39\% average) for pig feeding ( $n=48$, eight animals per treatment). The composition and quality traits (fat content, cooking losses, lipid oxidation, fatty acid profile, volatile profile and sensory analysis) of cooked loin, as affected by dietary CLA, MUFA, and CLA $\times$ MUFA interaction were studied. CLA and CLA $\times$ MUFA did not affect the intramuscular fat content, cooking losses, lipid oxidation, volatile profile and sensory traits of cooked meat. Therefore, CLA could be supplemented to the pig diet without detriment of the measured quality traits of cooked meat, and regardless of the MUFA level of pig diets. Dietary CLA increased the content of SFA and decreased the level of MUFA of meat, and led to a CLA enrichment, regardless the MUFA level of pig diets, but the content of CLA isomers of fresh meat decreased after the cooking process.
\end{abstract}

(c) 2010 Elsevier Ltd. All rights reserved.

\section{Introduction}

The supplementation of swine feeding with conjugated linoleic acid (CLA) has been suggested as an interesting approach for improving the meat quality traits, and at the same time for obtaining meat and meat products enriched in CLA (Martin, Muriel, Gonzalez, Viguera, \& Ruiz, 2008e; Schmid, Collomb, Sieber, \& Bee, 2006). The increase in the intramuscular fat content or the lower lipid oxidation of pork from CLA-fed pigs are also desirable effects, achieved by increasing the dietary CLA in pig feeding (Dugan, Aalhus, Jeremiah, Kramer, \& Schaefer, 1999; Joo, Lee, Ha, \& Park, 2002; Martin et al., 2008e). However, both effects are still uncertain, since other studies have not found an implication of dietary CLA on such traits (reviewed by Hur, Park, and Joo (2006)). On the other hand, dietary CLA supplementation also leads to increasing proportions of saturated fatty acids (SFA), while decreasing that of MUFA in pig tissues (Corino, Magni, Pastorelli, Rossi, \& Mourot, 2003; Dugan et al., 1999; Joo et al., 2002; Martin, Muriel, Antequera, PerezPalacios, \& Ruiz, 2008d; Martin et al., 2008e). Such an increase in the ratio SFA to unsaturated fatty acids could have negative health implications from the consumer standpoint (Department of Health, 1994). In previous works (Martin, Antequera, Gonzalez, LopezBote, \& Ruiz, 2007; Martin et al., 2008e, 2008d), we have proposed the inclusion of high levels of MUFA in pig diets when using dietary CLA as an effective strategy for counteracting the decrease in MUFA caused by CLA.

\footnotetext{
* Corresponding author. Tel.: +34 927 257123; fax: +34 927257110.

E-mail address: jruiz@unex.es (J. Ruiz).
}

Since dietary CLA may affect the intramuscular fat content and the fatty acid composition of meat lipids, such effects might in turn influence the volatile profile and sensory traits of the derived cooked pork. This is because the thermally induced reactions involving the lipid fraction during cooking, contributes to the characteristic flavour and sensory quality traits of cooked meat and meat products (Cameron \& Enser, 1991; Muriel, Ruiz, Martin, Petron, \& Antequera, 2004). In general, dietary CLA has shown a lack of effect on the sensory attributes in cooked pork (Dugan et al., 1999; Migdal et al., 2004; Wiegand, Sparks, Parrish, \& Zimmerman, 2002), and no previous studies have been found in the scientific literature regarding the effect of dietary CLA on the volatile profile of cooked pork. In addition, no information regarding the effects of combining levels of dietary CLA and MUFA in pig diets on the sensory quality and flavour of cooked pork has been previously reported.

On the other hand, cooking processes may alter the original CLA content of fresh meat, but this is an unclear subject. Both the formation and destruction of CLA isomers have been reported in the scientific literature for cooked beef (Ha, Grimm, \& Pariza, 1989; Shantha, Crum, \& Decker, 1994), cooked lamb (Maranesi et al., 2005), or for other CLA-containing foods, such as CLA-fortified dairy products (Rodriguez-Alcala \& Fontecha, 2007). According to our knowledge, previous studies on CLA-enriched pork have not reported the changes in the CLA levels of the raw material after the cooking process. This subject is of interest in order to elucidate if the enrichment with CLA by dietary strategies would remain in the cooked meat.

The mentioned parameters affected by dietary CLA, including the intramuscular fat content, lipid oxidation, fatty acid and 
volatile compounds and sensory analysis, are parameters related to the quality traits of meat and meat products. Therefore, the present work aimed to examine the influence of combining different levels of CLA and MUFA in the pig diets on the composition and quality traits of cooked pork, as well as the effect of the cooking process on the final CLA content of the product.

\section{Materials and methods}

\subsection{Animals, feeding and sampling procedure}

Three levels ( $0 \%, 1 \%$ and $2 \%$ ) of commercial enriched CLA supplementation (CLA-60, BASF, Dortmund, Germany), containing approximately $56 \%$ of CLA isomers (28\% cis-9, trans- 11 and $28 \%$ trans-10, cis-12), and two levels of MUFA (low, 19\% and high, $39 \%$ ) were combined for pig feeding (Table 1). All diets were for-

Table 1

Ingredients, chemical and fatty acid composition of the experimental treatments for pig feeding.

\begin{tabular}{|c|c|c|c|c|c|c|}
\hline & \multicolumn{3}{|c|}{ Low MUFA feed } & \multicolumn{3}{|c|}{ High MUFA feed } \\
\hline & $0 \%$ CLA & $1 \%$ CLA & $2 \%$ CLA & $0 \%$ CLA & $1 \%$ CLA & $2 \%$ CLA \\
\hline \multicolumn{7}{|l|}{ Ingredient (\%) } \\
\hline Barley & 53.3 & 53.3 & 53.3 & 53.3 & 53.3 & 53.3 \\
\hline Wheat & 15.0 & 15.0 & 15.0 & 15.0 & 15.0 & 15.0 \\
\hline Bran & 8.0 & 8.0 & 8.0 & 8.0 & 8.0 & 8.0 \\
\hline $\begin{array}{l}\text { Soybean meal } \\
\quad 44 \%\end{array}$ & 16.0 & 16.0 & 16.0 & 16.0 & 16.0 & 16.0 \\
\hline Palm oil & 1.6 & 1.1 & 0.6 & 1.0 & 0.5 & 0.0 \\
\hline Soy olein & 0.4 & 0.4 & 0.4 & 0.0 & 0.0 & 0.0 \\
\hline Olive olein & 0.0 & 0.0 & 0.0 & 3.0 & 3.0 & 3.0 \\
\hline $\begin{array}{l}\text { Hydrogenated } \\
\text { stearin } \\
\text { palm }\end{array}$ & 3.0 & 2.5 & 2.0 & 1.0 & 0.5 & 0.0 \\
\hline CLA & 0.0 & 1.0 & 2.0 & 0.0 & 1.0 & 2.0 \\
\hline Carbonate & 1.2 & 1.2 & 1.2 & 1.2 & 1.2 & 1.2 \\
\hline Phosphate & 0.4 & 0.4 & 0.4 & 0.4 & 0.4 & 0.4 \\
\hline Salt & 0.4 & 0.4 & 0.4 & 0.4 & 0.4 & 0.4 \\
\hline L-Lysine 50 & 0.17 & 0.17 & 0.17 & 0.17 & 0.17 & 0.17 \\
\hline L-Threonine & 0.03 & 0.03 & 0.03 & 0.03 & 0.03 & 0.03 \\
\hline Coline 75 & 0.04 & 0.04 & 0.04 & 0.04 & 0.04 & 0.04 \\
\hline $\begin{array}{l}\text { Vitamin and } \\
\text { mineral } \\
\text { premix }\end{array}$ & 0.5 & 0.5 & 0.5 & 0.5 & 0.5 & 0.5 \\
\hline \multicolumn{7}{|c|}{ Chemical composition (\%) } \\
\hline Dry matter & 89.2 & 89.6 & 89.4 & 89.3 & 89.5 & 89.6 \\
\hline Ash & 4.9 & 5.1 & 5.0 & 5.1 & 5.6 & 5.3 \\
\hline Crude fibre & 4.2 & 4.3 & 4.1 & 4.7 & 4.3 & 4.6 \\
\hline Crude fat & 7.7 & 6.9 & 7.3 & 7.2 & 7.1 & 6.8 \\
\hline Crude protein & 16.4 & 16.0 & 15.8 & 16.7 & 16.5 & 15.8 \\
\hline $\begin{array}{l}\text { Nitrogen free } \\
\text { extractives }\end{array}$ & 62.8 & 64.1 & 64.0 & 62.4 & 62.7 & 63.8 \\
\hline $\begin{array}{l}\text { Energy (kcal/ } \\
\quad \text { kg) }\end{array}$ & 3238.8 & 3240.8 & 3242.8 & 3257.8 & 3259.8 & 3261.8 \\
\hline \multicolumn{7}{|c|}{ Fatty acid composition (\%) } \\
\hline $\mathrm{C} 14: 0$ & 0.8 & 0.6 & 0.5 & 0.5 & 0.3 & 0.3 \\
\hline C16:0 & 35.3 & 30.4 & 25.6 & 25.4 & 19.7 & 15.0 \\
\hline C16:1 & 0.1 & 0.1 & 0.1 & 0.5 & 0.4 & 0.4 \\
\hline C18:0 & 22.8 & 20.1 & 16.6 & 11.4 & 7.6 & 4.6 \\
\hline C18:1 n-9 & 18.1 & 18.0 & 18.7 & 37.8 & 37.9 & 37.8 \\
\hline C18:2 n-6 & 19.9 & 20.2 & 19.8 & 20.6 & 22.2 & 22.5 \\
\hline C18:3 n-3 & 1.8 & 1.7 & 1.6 & 1.8 & 2.1 & 2.1 \\
\hline $\begin{array}{l}\text { cis-9, trans-11 } \\
\text { CLA }\end{array}$ & 0.0 & 3.9 & 8.0 & 0.0 & 4.3 & 7.9 \\
\hline $\begin{array}{l}\text { trans-10, cis- } \\
12 \text { CLA }\end{array}$ & 0.0 & 3.7 & 7.9 & 0.0 & 4.2 & 8.1 \\
\hline SFA & 59.7 & 52.0 & 43.5 & 38.8 & 28.4 & 20.6 \\
\hline MUFA & 18.8 & 18.6 & 19.2 & 38.9 & 38.8 & 38.7 \\
\hline PUFA $^{\mathrm{a}}$ & 21.5 & 21.9 & 21.5 & 22.4 & 24.4 & 24.7 \\
\hline
\end{tabular}

a Excluding CLA isomers. mulated to provide similar protein and energy levels, fulfilling the advised nutritional needs for female pigs at considered ages by the National Research Council (1998).

The experiment was conducted using 288 finishing gilts (Large White $\hat{\sigma} \times$ Landrace $\times$ Large White \%). Pigs weighting $70 \mathrm{~kg}$ and at about 140 days of age were randomly allotted to the six different feeding treatments in four replicates of each treatment (12 pigs per replicate). The pigs were housed in an environmentally controlled experimental grower/finisher shed. The pigs were group-housed (12 pigs per pen) and had ad libitum access to feed (single-space dry feeders) and water (nipple drinkers) to a final average weight of $107 \mathrm{~kg}$. After fattening (53 days), all pigs were slaughtered at a local slaughterhouse by electrical stunning and exsanguinations; the whole loin from 48 slaughtered pigs (eight animals randomly selected from each treatment) were taken within 10 min after bleeding, and were vacuum-packaged and frozen at $-80{ }^{\circ} \mathrm{C}$ until required. The rest of the slaughtered animals were considered for the study of the effect of dietary treatments on the productive and carcass quality traits of pigs, as previously reported (Martin et al., 2008e).

\subsection{Cooking process}

Frozen loins were cut into chops of $1.5 \mathrm{~cm}$ thick using an electrical meat saw (Mainca BM-170, Barcelona, Spain). The chops were then thawed at $4{ }^{\circ} \mathrm{C}$ for $24 \mathrm{~h}$. The external fat of the chops was trimmed. Sodium chloride was added at equal grams in the upper and the lower surfaces of the chop ( $0.25 \% \mathrm{w} / \mathrm{w}$ per surface). Samples were grilled in a griddle (GR7445 Natur Chef, Ufesa, Spain) at $225^{\circ} \mathrm{C}$, controlled by an infrared thermometer for $4 \mathrm{~min}(2 \mathrm{~min}$ per each side of the chop), and a core temperature of $72{ }^{\circ} \mathrm{C}$ controlled by a temperature probe. The chops were pre-weighted before cooking and after cooking, thus, cooking losses were estimated.

\subsection{Sensory analysis}

Cooked chops were assessed by a trained panel of 17 members, using a descriptive analysis method. The sensory traits, their definitions and extremes are explained in Table 2. The questions were presented to assessors in the normal perception order, as follows: visual analysis, odour perception, lean texture, taste and flavour. The panelists were selected from faculty, staff and researchers of the University using individual taste, flavour and aroma recognition thresholds. The selected subjects underwent further training in meat and meat products sensory characteristics during 2 years, and have subsequently participated in several panels for cooked meat sensory analysis.

Five out of the eight loins of each group were randomly selected and subjected to sensory analysis, in order to reduce the number of analysed samples and thus, avoid the exhaustion of the panel. Three loins from different groups were evaluated in each session. The sample order was randomised. The sessions were held $3 \mathrm{~h}$ after breakfast. A portion of each freshly cooked chop was given to the panellists served on glass plates. A glass of water was provided for each assessor. All sessions were done in a six-booth sensory panel room at $22{ }^{\circ} \mathrm{C}$ equipped with white fluorescent lighting (220$230 \mathrm{~V}, 35 \mathrm{~W}$ ). Ten traits concerning the sensory characteristics of cooked pork (Table 2), grouped under appearance, texture, taste and flavour were assessed by the panellists in a $10 \mathrm{~cm}$ unstructured line, ranging from "less" to "more". The FIZZ Network (version 1.01, Biosystems, France) program was used for the session performances; all data were recorded. After cooking, a portion of each cooked chop was vacuum-packaged and stored at $-80^{\circ} \mathrm{C}$ until laboratory analysis. 
Table 2

Sensory attribute, definitions and extremes of each attribute scored in an unstructured line of $10 \mathrm{~cm}$.

\begin{tabular}{|c|c|c|}
\hline Sensory trait & Definition & Extremes \\
\hline $\begin{array}{l}\text { Appearance } \\
\text { Brightness }\end{array}$ & Intensity of brightness on the lean surface & Dull to very bright \\
\hline $\begin{array}{l}\text { Texture } \\
\text { Hardness } \\
\text { Chewiness } \\
\text { Juiciness } \\
\text { Pastiness }\end{array}$ & $\begin{array}{l}\text { Effort required to bite through lean and to convert the sample to a swallowable state } \\
\text { Work required to masticate the sample before swallowing } \\
\text { Impression of lubricated food during chewing } \\
\text { Pasty feeling inside the mouth during chewing }\end{array}$ & $\begin{array}{l}\text { Very tender to very firm } \\
\text { Very low to very high } \\
\text { Not to very juicy } \\
\text { Very low to very high }\end{array}$ \\
\hline $\begin{array}{l}\text { Taste } \\
\text { Saltiness }\end{array}$ & Level of salt taste & Not to very salty \\
\hline $\begin{array}{l}\text { Flavour } \\
\text { Flavour intensity } \\
\text { Flavour after-taste } \\
\text { Rancid } \\
\text { Umami }\end{array}$ & $\begin{array}{l}\text { Level of overall flavour } \\
\text { Intensity and duration of the flavour after sample is swallowed } \\
\text { Intensity of rancid flavour } \\
\text { Intensity of umami flavour }\end{array}$ & $\begin{array}{l}\text { Flavourless to very intense flavour } \\
\text { Very low to very high } \\
\text { Very low to very high } \\
\text { Very low to very high }\end{array}$ \\
\hline
\end{tabular}

\subsection{Chemical analyses}

The analysis of the feeds was performed according to the Association of Official Analytical Chemists (2000); crude protein (reference 954.01), crude fat (reference 920.39), crude fibre (reference 962.09) and ash (reference 942.05). The obtained composition of the diets is shown in Table 1 . The total lipids were extracted with chloroform:methanol $(2: 1 \mathrm{v} / \mathrm{v})$ according to the method of Folch, Lees, and Stanley (1957). The thiobarbituric reactive substances (TBARs) were measured following the method of Salih, Smith, Price, and Dawson (1987), and were expressed as mg malondialdehyde (MDA) per kg sample.

\subsection{Fatty acid analysis}

The fatty acid methyl esters (FAMEs) of total lipids of samples were obtained by acidic transesterification following the method described by Sandler and Karo (1992). FAMEs were analysed by gas chromatography using a Hewlett-Packard HP-5890A gas chromatograph, equipped with an on-column injector and a flame ionisation detector, using a polyethylenglycol capillary column (Supelcowax-10, Supelco, Bellefonte, PA) $(60 \mathrm{~m} \times 0.32 \mathrm{~mm}$ i.d. $\times 0.25 \mu \mathrm{m}$ film thickness). The gas chromatograph oven program temperature was as follows: initial temperature of $180^{\circ} \mathrm{C}$, $5{ }^{\circ} \mathrm{C} / \mathrm{min}$ to $200^{\circ} \mathrm{C} ; 40 \mathrm{~min}$ at this temperature and thereafter $5^{\circ} \mathrm{C} / \mathrm{min}$ to $250^{\circ} \mathrm{C}$, and then kept for an additional $21 \mathrm{~min}$. The injector and detector temperatures were $250{ }^{\circ} \mathrm{C}$. The carrier gas was helium at a flow rate of $0.8 \mathrm{ml} / \mathrm{min}$. Individual FAME peaks were identified by comparison of their retention times with those of standards (Sigma, St. Louis, MO). Tridecanoic acid was used as internal standard.

\subsection{Volatile compounds}

The volatile compounds of cooked chops were determined by headspace-solid phase microextraction (HS-SPME) (Supelco Co., Bellefonte, PA) using a fibre coated with carboxen-poly (dimethylsiloxane)-divinylbenzene $(50 / 30 \mu \mathrm{m}$ thickness) (Garcia-Esteban, Ansorena, Astiasaran, Martin, \& Ruiz, 2004). The muscle samples were ground with a commercial grinder. A portion of $0.5 \mathrm{~g}$ was weighed into a $4 \mathrm{ml}$ screw-capped vial, and $1.5 \mathrm{ml}$ of saturated salt solution was added. The extractions were performed in a thermostatised water bath at $40^{\circ} \mathrm{C}$ for $30 \mathrm{~min}$ under stirring. Before extraction, the samples were equilibrated for $10 \mathrm{~min}$ at the same temperature used for extraction. Prior to analysis, the SPME fibre was preconditioned at $250^{\circ} \mathrm{C}$ for $60 \mathrm{~min}$ in the GC injection port. The analyses were performed using an Agilent 6890 series gas chromatograph (Agilent, Avondale, USA) coupled to a mass selective detector (Agilent 5973, Agilent, Avondale, USA). The analytes were separated using a 5\% Phenyl-Methyl Silicone (HP-5) bonded phase fused silica capillary column (Hewlett-Packard, $50 \mathrm{~m} \times 0.32 \mathrm{~mm}$ i.d., film thickness $1.05 \mu \mathrm{m}$ ), operating at $45 \mathrm{kPa}$ of column head pressure, resulting in a flow of $1.3 \mathrm{ml} / \mathrm{min}$ at $40{ }^{\circ} \mathrm{C}$. The SPME fibre was desorbed during $30 \mathrm{~min}$. The injection port was in splitless mode. The temperature program was $40^{\circ} \mathrm{C}$ during $10 \mathrm{~min}$, raised to $200^{\circ} \mathrm{C}$ at a rate of $5^{\circ} \mathrm{C} / \mathrm{min}$, and then raised to $250{ }^{\circ} \mathrm{C}$ at a rate of $20^{\circ} \mathrm{C} / \mathrm{min}$, maintained at this temperature for $5 \mathrm{~min}$. The transfer line to the mass spectrometer was hold at $280^{\circ} \mathrm{C}$. The mass spectra were obtained by electronic impact at $70 \mathrm{eV}$, a multiplier voltage of $1756 \mathrm{~V}$, and, by collecting data at a rate of $1 \mathrm{scan} / \mathrm{s}$ over the $\mathrm{m} / \mathrm{z}$ range 30-300. $n$-Alkanes (Sigma $\mathrm{R}-8769$ ) were analysed under the same conditions to calculate the retention indices (RI) for the volatiles. The compounds were identified by comparison with the mass spectrum and the RI of commercial reference compounds (Sigma-Aldrich; Steinhein, Germany), and with those described on the web at http://webbook.nist.gov/, and in the Wiley library. Results from the volatile analysis are given in area units (AU).

\subsection{Statistical analysis}

An individual pig was the experimental unit for analysis of all data. Statistical analyses were performed by means of the general linear models procedure of the SPSS statistical software (V 15.0). The effect of CLA and MUFA content of the diets and their interaction $(C L A \times$ MUFA) on fat content, cooking losses, TBARs values, fatty acid profile, volatile profile, as well as the sensory traits of chops was evaluated by a two-way analysis of variance (ANOVA). Differences were considered significant at $p \leqslant 0.05$. When the effect of any of the factors was significant, the differences between groups were analysed by the Tukey's post hoc test. The effect of heat treatment $(T)$ and its respective interaction with CLA $(\mathrm{T} \times \mathrm{CLA})$, MUFA $(\mathrm{T} \times \mathrm{MUFA})$ and CLA $\times$ MUFA $(\mathrm{T} \times \mathrm{CLA} \times \mathrm{MUFA})$ on the change of the CLA content was evaluated by a two-way analysis of variance. Differences were considered significant at $p \leqslant 0.05$.

\section{Results and discussion}

\subsection{Fat content and cooking losses}

The same loins assayed in the present work were previously analysed for their composition (Martin et al., 2008e), and a significant effect of dietary CLA on the intramuscular fat content of a 
Table 3

Fat content and weight losses (\%) of cooked chops ( $n=8$ for each group) from pigs fed different levels of CLA and MUFA.

\begin{tabular}{|c|c|c|c|c|c|c|c|c|c|c|}
\hline & \multicolumn{3}{|c|}{ Low MUFA } & \multicolumn{3}{|c|}{ High MUFA } & \multirow[t]{2}{*}{ SEM } & \multicolumn{3}{|l|}{$p$} \\
\hline & $0 \%$ CLA & $1 \%$ CLA & $2 \%$ CLA & $0 \%$ CLA & $1 \%$ CLA & $2 \%$ CLA & & CLA & MUFA & CLA $\times$ MUFA \\
\hline Fat content & 2.1 & 2.1 & 2.4 & 2.2 & 2.5 & 2.4 & 0.1 & 0.771 & 0.539 & 0.816 \\
\hline Cooking losses & 17.1 & 13.2 & 12.8 & 13.3 & 14.8 & 16.2 & 0.4 & 0.625 & 0.682 & 0.013 \\
\hline
\end{tabular}

fresh loin was reported. On the contrary, in the present work, it was found that the intramuscular fat content of cooked chops was not influenced by CLA, MUFA or CLA $\times$ MUFA interaction (Table 3). The distribution, width, length and size of marbling fat of pork are quite irregular. In addition, the sampling location in the fresh loin and cooked loin was not exactly the same. All these reasons could explain the different results between the intramuscular fat content of the fresh and cooked loin, as affected by the dietary treatments.

The cooking losses were not influenced by the dietary CLA or dietary MUFA levels, but this trait was affected by the combination of levels of both factors in the pig diets [ $($ CLA $\times$ MUFA $)<0.05$ ] (Table 3). Thus, curiously, the combination of CLA and low MUFA levels in the pig diets seemed to lead to lower weight losses of chops (17.1\% for 0\% CLA-Low MUFA diets and $12.8 \%$ for $2 \%$ CLALow MUFA diets), whereas the combination of CLA and high MUFA levels in the pig diets seemed to cause higher weight losses of cooked pork (13.3\% for 0\% CLA-High MUFA diets and 16.2\% for $2 \%$ CLA-High MUFA diets). Nevertheless, these results did not seem to be relevant, since no differences were detected by the Tukey's post hoc test. Similarly to our results for the CLA-Low MUFA treatments, Joo et al. (2002) reported a decreased purge loss in fresh pork loin due to an increased CLA content; the authors suggested that this could be due to the stability of the cell membrane lipids, since they observed a delay in the lipid oxidation for the CLA groups. Therefore, it seems that dietary CLA or its combination with MUFA levels does not influence the quality traits of cooked loin, related to its fat content and cooking losses.

\subsection{Fatty acid profile}

The fatty acid profile of the cooked chops is shown in Table 4. Cooked pork showed a higher total SFA content $(p<0.001)$ and a lower total MUFA content $(p=0.047)$ due to dietary CLA. This lipid composition of the cooked loin determined by dietary CLA was a reflection of the lipid composition of the fresh meat before cooking, as previously reported (Martin et al., 2008e). This would suggest that the effect of dietary CLA on modifying the fatty acid profile of raw pork, still remains in the cooked pork. The modification of the fatty acid profile by dietary CLA is an effect found in most of studies, and has been related to an inhibitory effect of CLA on desaturase activities (Corino et al., 2003; Dugan et al., 1999; Joo et al., 2002). In a previous work (Martin et al., 2008e) it was revealed that such an effect of CLA was not influenced by the MUFA

Table 4

Fatty acid profile cooked loin (g/100 g FAMEs) from pigs fed different CLA and MUFA levels ( $n=8$ for each group).

\begin{tabular}{|c|c|c|c|c|c|c|c|c|c|}
\hline & \multicolumn{3}{|c|}{ CLA level $^{\mathrm{A}}$} & \multicolumn{2}{|c|}{ MUFA level } & \multirow[t]{2}{*}{ SEM } & \multicolumn{3}{|l|}{$p$} \\
\hline & $0 \%$ & $1 \%$ & $2 \%$ & Low & High & & CLA & MUFA & $\mathrm{CLA} \times \mathrm{MUFA}$ \\
\hline $\mathrm{C} 12: 0$ & 0.03 & 0.03 & 0.03 & 0.03 & 0.03 & 0.00 & 0.065 & 0.419 & 0.088 \\
\hline $\mathrm{C} 14: 0$ & $0.71^{\mathrm{b}}$ & $0.78^{\mathrm{b}}$ & $0.93^{\mathrm{a}}$ & 0.81 & 0.81 & 0.03 & 0.002 & 0.859 & 0.271 \\
\hline $\mathrm{C} 14: 1 n-5$ & 0.14 & 0.14 & 0.15 & 0.14 & 0.14 & 0.01 & 0.923 & 0.854 & 0.260 \\
\hline C15:0 & 0.04 & 0.05 & 0.04 & 0.04 & 0.05 & 0.00 & 0.410 & 0.265 & 0.504 \\
\hline C16:0 & $19.89^{b}$ & $20.74^{\mathrm{ab}}$ & $21.87^{a}$ & 20.88 & 20.80 & 0.25 & 0.002 & 0.973 & 0.060 \\
\hline C16:1 n-7 & 2.40 & 2.33 & 2.47 & 2.43 & 2.38 & 0.06 & 0.702 & 0.677 & 0.517 \\
\hline C17:0 & 0.21 & 0.21 & 0.21 & 0.21 & 0.21 & 0.01 & 0.893 & 0.729 & 0.284 \\
\hline C17:1 & 0.17 & 0.15 & 0.15 & 0.16 & 0.15 & 0.01 & 0.447 & 0.454 & 0.052 \\
\hline C18:0 & $12.90^{\mathrm{b}}$ & $13.99^{\mathrm{ab}}$ & $14.75^{\mathrm{a}}$ & 13.92 & 13.83 & 0.23 & 0.002 & 0.915 & 0.527 \\
\hline C18:1 n-9 & 41.52 & 37.90 & 37.50 & 38.48 & 39.54 & 0.72 & 0.037 & 0.516 & 0.656 \\
\hline $\mathrm{C} 18: 2 n-6$ & 13.69 & 14.88 & 13.43 & 14.31 & 13.62 & 0.47 & 0.476 & 0.524 & 0.524 \\
\hline C18:3 n-6 & $0.15^{\mathrm{a}}$ & $0.12^{\mathrm{ab}}$ & $0.10^{\mathrm{b}}$ & 0.12 & 0.12 & 0.01 & 0.027 & 0.951 & 0.434 \\
\hline $\mathrm{C} 18: 3 n-3$ & 0.49 & 0.50 & 0.50 & 0.49 & 0.50 & 0.01 & 0.852 & 0.374 & 0.424 \\
\hline C20:0 & 0.17 & 0.16 & 0.17 & 0.17 & 0.16 & 0.01 & 0.399 & 0.577 & 0.270 \\
\hline $\mathrm{C} 20: 1 n-9$ & 0.72 & 0.68 & 0.65 & 0.67 & 0.69 & 0.02 & 0.208 & 0.528 & 0.307 \\
\hline C20:2 n-6 & 0.40 & 0.43 & 0.40 & 0.41 & 0.41 & 0.01 & 0.294 & 0.815 & 0.385 \\
\hline$C 20: 3 n-6$ & 0.54 & 0.51 & 0.41 & 0.49 & 0.48 & 0.03 & 0.150 & 0.737 & 0.493 \\
\hline$C 20: 4 n-6$ & 4.20 & 3.93 & 3.42 & 3.90 & 3.80 & 0.24 & 0.445 & 0.821 & 0.707 \\
\hline C21:0 & 0.09 & 0.10 & 0.09 & 0.09 & 0.10 & 0.00 & 0.079 & 0.014 & 0.948 \\
\hline C20:5 n-3 & 0.22 & 0.22 & 0.22 & 0.22 & 0.22 & 0.01 & 0.994 & 0.956 & 0.631 \\
\hline $\mathrm{C} 22: 0$ & 0.02 & 0.03 & 0.02 & 0.02 & 0.03 & 0.00 & 0.181 & 0.309 & 0.378 \\
\hline $\mathrm{C} 22: 1 n-9$ & 0.03 & 0.04 & 0.03 & 0.03 & 0.04 & 0.00 & 0.409 & 0.039 & 0.446 \\
\hline$C 22: 2 n-6$ & 0.05 & 0.05 & 0.04 & 0.04 & 0.05 & 0.00 & 0.064 & 0.266 & 0.930 \\
\hline $\mathrm{C} 22: 5 n-3$ & 0.51 & 0.49 & 0.39 & 0.49 & 0.45 & 0.03 & 0.226 & 0.505 & 0.736 \\
\hline C24:0 & 0.57 & 0.64 & 0.52 & 0.57 & 0.58 & 0.04 & 0.514 & 0.863 & 0.448 \\
\hline $\mathrm{C} 24: 1 n-9$ & 0.02 & 0.03 & 0.02 & 0.02 & 0.02 & 0.00 & 0.245 & 0.139 & 0.479 \\
\hline$C 22: 6 n-3$ & 0.27 & 0.33 & 0.29 & 0.29 & 0.30 & 0.02 & 0.582 & 0.790 & 0.485 \\
\hline Cis-9, trans-11 CLA & $0.14^{\mathrm{c}}$ & $0.42^{\mathrm{b}}$ & $0.75^{\mathrm{a}}$ & 0.45 & 0.43 & 0.04 & 0.000 & 0.750 & 0.995 \\
\hline Trans- 10 , cis- 12 CLA & $0.04^{\mathrm{c}}$ & $0.18^{\mathrm{b}}$ & $0.36^{\mathrm{a}}$ & 0.19 & 0.19 & 0.02 & 0.000 & 0.941 & 0.955 \\
\hline Total SFA & $34.63^{\mathrm{b}}$ & $36.73^{\mathrm{a}}$ & $38.63^{\mathrm{a}}$ & 36.74 & 36.60 & 0.43 & 0.000 & 0.971 & 0.098 \\
\hline Total MUFA & 45.00 & 41.27 & 40.97 & 41.93 & 42.96 & 0.76 & 0.047 & 0.559 & 0.602 \\
\hline Total PUFA ${ }^{\mathrm{B}}$ & 20.52 & 21.46 & 19.20 & 20.76 & 19.95 & 0.79 & 0.577 & 0.643 & 0.591 \\
\hline
\end{tabular}

A Different letters within the same row differed significantly $(p \leqslant 0.05)$.

B Excluding CLA isomers. 
level of pig diets. Similarly, the MUFA level of the treatments or its interaction with the CLA levels did not affect the fatty acid profile of pork after cooking in the present study, as shown in Table 4.

As it can be observed in Table 4, the higher the CLA level of the pig diets the higher was the CLA content of cooked pork. The level of the cis-9, trans-11 CLA isomer was greater than that of the trans10 , cis-12 CLA isomer. The CLA content of cooked pork was independent on the MUFA level of pig diets. Both the progressive accumulation of CLA isomers with the level of CLA supplementation, as well as the higher proportion of the cis-9, trans-10 CLA isomer of cooked pork, were a reflection of the same behaviours observed for the fresh pork before cooking (Fig. 1). However, as it can be observed in Fig. 1, the levels of both CLA isomers of cooked pork were lower compared to the levels of both CLA isomers of fresh pork. Moreover, the content of the trans-10, cis-12 CLA isomer decreased after cooking for all the assayed levels of CLA supplementation, whereas the content of the cis-9, trans-11 CLA isomer only decreased for the $1 \%$ and $2 \%$ CLA levels in pig diets. The changes of the content of both CLA isomers were not influenced by the MUFA levels of pig diets $[p(T \times$ MUFA $)$ and $p(T \times C L A \times$ MUFA $)>0.05$ for both CLA isomers].
It has been suggested that the cooking process may alter the original CLA content of fresh meat, but this effect remains still unclear, since both the formation of CLA isomers by thermal oxidation of C18:2, and the destruction of CLA isomers by high cooking temperatures and oxidative reactions, have been reported in the scientific literature. Thus, Ha et al. (1989) found an increase in the CLA content of grilled beef compared to uncooked fresh beef. Shantha et al. (1994) also reported slight increases (not significant, except in one meat sample) of CLA when cooked beef steaks were compared with the raw ones. On the contrary, Maranesi et al. (2005) reported that both broiling and microwave did not influence the CLA content in lamb rib-loins. Regarding other CLA-enriched foodstuffs, Rodriguez-Alcala and Fontecha (2007) have recently reported changes in the content of CLA isomers due to the processing of CLA-fortified dairy products. These authors did not find significant changes in the two major CLA isomers (cis-9, trans-11 CLA and trans-10, cis-12 CLA), but they found a significant loss or disappearance of some minor CLA isomers. To the best of our knowledge, information regarding the change in the content of CLA isomers of CLA-enriched pork after cooking processes, has not been previously reported. The obtained results in the present
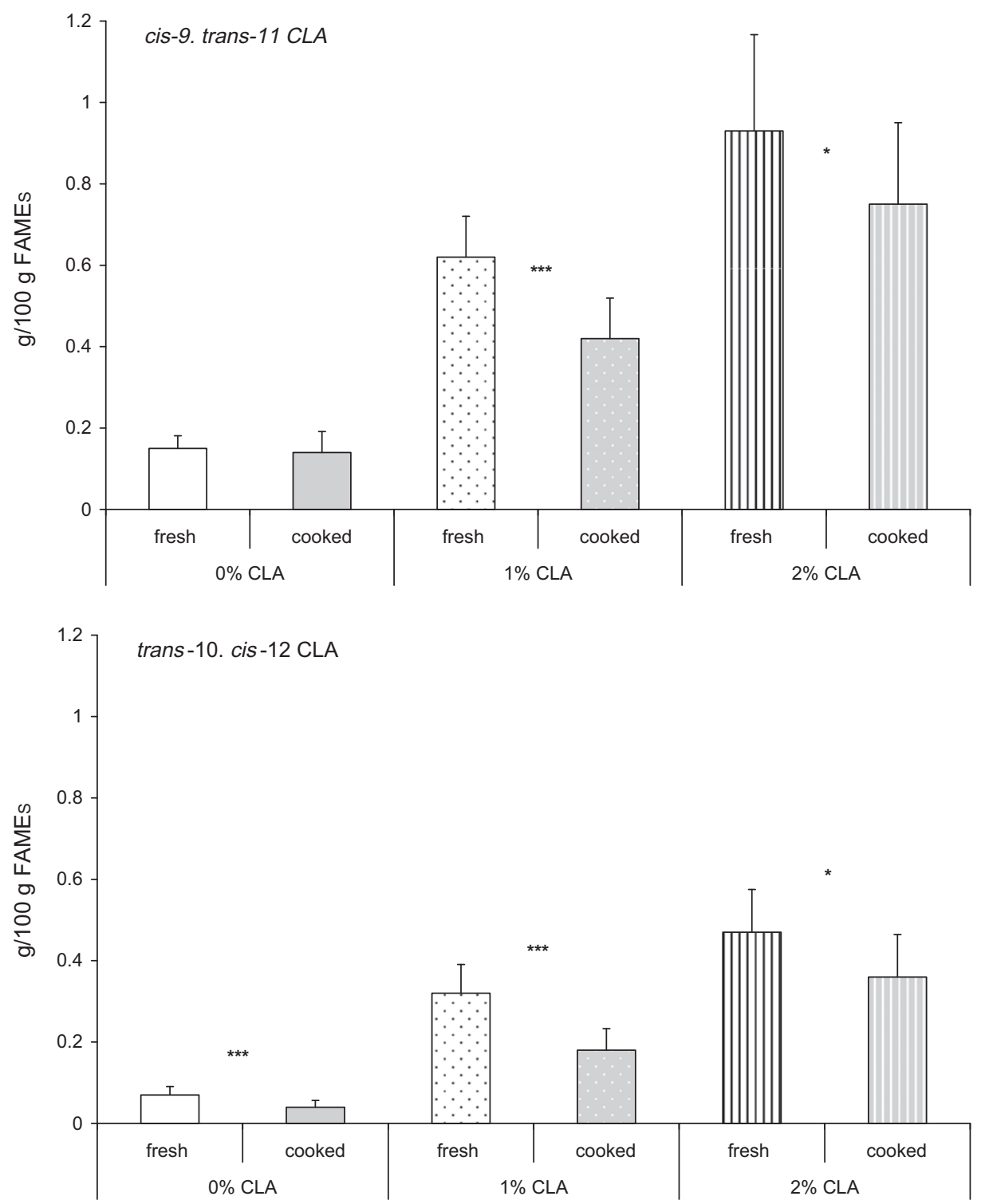

Fig. 1. Content of CLA isomers ( $g / 100 \mathrm{~g}$ FAMEs) of fresh loin and cooked loin from pigs fed different levels of CLA. 
work showed that the CLA content of fresh pork decreased after the cooking process. Moreover, the extent of these changes seemed to be different depending on the specific CLA isomer. Finally, the present work revealed that the MUFA level of the feeds when CLA is supplemented to pig diets was not involved in the changes in the content of the CLA isomers during the cooking process.

\subsection{Lipid oxidation}

Dietary CLA, MUFA or the interaction CLA $\times$ MUFA did not affect the lipid oxidation of cooked pork [ $p$ (CLA), $p$ (MUFA), $p($ CLA $\times$ MUFA $)>0.05]$. The TBARs values were $0.22 \pm 0.08 \mathrm{mg}$ MDA $/ \mathrm{kg}$ for $0 \%$ CLA-Low MUFA, $0.20 \pm 0.11 \mathrm{mg} \mathrm{MDA} / \mathrm{kg}$ for $1 \%$ CLA-Low MUFA, $0.25 \pm 0.08 \mathrm{mg}$ MDA/kg for $2 \%$ CLA-Low MUFA, $0.22 \pm 0.04 \mathrm{mg} \mathrm{MDA} / \mathrm{kg}$ for $0 \%$ CLA-High MUFA, $0.23 \pm 0.09 \mathrm{mg}$
MDA $/ \mathrm{kg}$ for $1 \%$ CLA-High MUFA, and $0.21 \pm 0.06 \mathrm{mg} \mathrm{MDA} / \mathrm{kg}$ for 2\% CLA-High MUFA. The susceptibility to lipid oxidation of the same fresh chops used in the present work was previously studied (Martin et al., 2008d). In that study, a lack of effect of dietary CLA, MUFA and of the interaction CLA $\times$ MUFA on induced lipid peroxidation of fresh loin was concluded, being in agreement with the results found in the present work for the cooked chops.

The role of CLA on lipid oxidation processes is a controversial matter that still remains unclear. Thus, both antioxidative, pro-oxidative and lack of effect of dietary CLA in lipid oxidative processes have been described (reviewed by Hur et al. (2006)). In agreement with the obtained results in the present work, van den Berg, Cook, and Tribble (1995) showed that CLA does not act as an efficient antioxidant, and Banni et al. (1998) did not find an antioxidant activity of CLA. However, several other works have clearly shown

Table 5

Volatile profile $\left(\mathrm{AU} \times 10^{4}\right)$ of cooked loin from pigs fed different levels of CLA and MUFA ( $n=8$ for each group).

\begin{tabular}{|c|c|c|c|c|c|c|c|c|c|c|}
\hline & \multicolumn{3}{|c|}{ CLA level } & \multicolumn{2}{|c|}{ MUFA level } & \multirow[t]{2}{*}{ SEM } & \multicolumn{3}{|l|}{$p$} & \multirow[t]{2}{*}{ Reliability $^{1}$} \\
\hline & $0 \%$ & $1 \%$ & $2 \%$ & Low & High & & CLA & MUFA & $\mathrm{CLA} \times \mathrm{MUFA}$ & \\
\hline \multicolumn{11}{|l|}{ Acids } \\
\hline Butanoic acid & 158.4 & 99.6 & 100.4 & 105.8 & 131.9 & 24.8 & 0.529 & 0.657 & 0.245 & B \\
\hline \multicolumn{11}{|l|}{ Alcohols } \\
\hline Ethanol & 522.6 & 733.6 & 875.0 & 680.1 & 751.7 & 120.4 & 0.537 & 0.778 & 0.195 & \\
\hline 1-Propanol & 58.6 & 60.4 & 66.5 & 60.6 & 64.1 & 5.1 & 0.882 & 0.955 & 0.305 & B \\
\hline 1-Hexanol & 88.1 & 67.7 & 53.1 & 56.8 & 75.4 & 9.2 & 0.243 & 0.224 & 0.479 & A \\
\hline 1-Octen-3-ol & 290.6 & 207.0 & 174.9 & 223.4 & 221.0 & 36.4 & 0.461 & 0.946 & 0.997 & A \\
\hline 2-Ethyl-1-hexanol & 36.4 & 54.2 & 28.0 & 46.1 & 37.0 & 11.0 & 0.611 & 0.755 & 0.665 & A \\
\hline \multicolumn{11}{|l|}{ Aldehydes } \\
\hline Acetaldehyde & 213.1 & 92.7 & 93.9 & 132.8 & 115.1 & 37.9 & 0.382 & 0.617 & 0.289 & B \\
\hline 3-Methyl butanal & 120.5 & 141.2 & 232.6 & 172.4 & 163.4 & 31.5 & 0.263 & 0.833 & 0.514 & A \\
\hline 2-Methyl butanal & 101.4 & 123.3 & 129.9 & 91.1 & 140.1 & 18.3 & 0.945 & 0.222 & 0.069 & A \\
\hline Pentanal & 790.0 & 803.9 & 522.4 & 643.0 & 751.3 & 115.4 & 0.553 & 0.667 & 0.971 & A \\
\hline Hexanal & 7490.7 & 7241.7 & 5660.0 & 6250.4 & 7344.4 & 1110.4 & 0.786 & 0.641 & 0.990 & A \\
\hline Heptanal & 626.2 & 637.8 & 761.3 & 732.5 & 622.0 & 94.5 & 0.825 & 0.597 & 0.901 & A \\
\hline Benzaldehyde & 212.2 & 151.8 & 174.5 & 163.5 & 193.4 & 18.5 & 0.467 & 0.446 & 0.803 & A \\
\hline Octanal & 11.4 & 10.4 & 7.6 & 10.2 & 9.5 & 1.1 & 0.398 & 0.805 & 0.900 & A \\
\hline 2-Octenal & 174.0 & 117.8 & 110.3 & 139.8 & 123.8 & 18.7 & 0.413 & 0.629 & 0.795 & A \\
\hline Nonanal & 1675.0 & 1620.9 & 1267.0 & 1559.1 & 1478.0 & 133.0 & 0.429 & 0.768 & 0.684 & B \\
\hline Decanal & 193.3 & 208.7 & 146.2 & 192.8 & 177.1 & 20.6 & 0.494 & 0.735 & 0.759 & B \\
\hline \multicolumn{11}{|l|}{ Aliphatic hydrocarbons } \\
\hline 2,3-Dimethyl butane & 350.6 & 252.6 & 243.4 & 216.9 & 344.0 & 38.7 & 0.463 & 0.102 & 0.504 & B \\
\hline 2-Methyl pentane & 3852.0 & 4257.3 & 4212.8 & 3820.3 & 4349.4 & 330.5 & 0.869 & 0.406 & 0.606 & B \\
\hline 3-Methyl pentane & 4291.4 & 4636.9 & 4585.7 & 4143.9 & 4865.4 & 355.9 & 0.918 & 0.333 & 0.672 & B \\
\hline Heptane & 272.9 & 179.0 & 217.3 & 178.0 & 243.1 & 25.3 & 0.533 & 0.563 & 0.662 & A \\
\hline Decane & 239.5 & 259.3 & 292.3 & 282.7 & 250.7 & 26.8 & 0.771 & 0.637 & 0.752 & A \\
\hline Dodecane & 106.7 & 87.2 & 139.4 & 110.6 & 108.2 & 19.6 & 0.541 & 0.894 & 0.665 & C \\
\hline \multicolumn{11}{|l|}{ Aromatic hydrocarbons } \\
\hline Methyl cyclopentane & 3012.2 & 3663.1 & 3107.4 & 3189.2 & 3337.1 & 312.4 & 0.684 & 0.828 & 0.553 & B \\
\hline Methyl benzene & 41.7 & 34.5 & 32.6 & 31.0 & 41.1 & 3.3 & 0.560 & 0.133 & 0.551 & B \\
\hline Ethyl benzene & 60.9 & 56.6 & 46.3 & 55.5 & 52.1 & 6.8 & 0.720 & 0.912 & 0.533 & B \\
\hline 1,2-Dimethyl benzene & 67.0 & 61.6 & 48.2 & 49.5 & 66.5 & 6.0 & 0.463 & 0.159 & 0.822 & B \\
\hline Ethenyl benzene & 132.3 & 159.3 & 158.0 & 155.0 & 146.0 & 22.6 & 0.869 & 0.863 & 0.816 & A \\
\hline \multicolumn{11}{|l|}{ Esters } \\
\hline Acetic acid ethyl ester & 2237.1 & 2508.3 & 2586.9 & 2154.2 & 2715.9 & 196.4 & 0.770 & 0.160 & 0.267 & B \\
\hline \multicolumn{11}{|l|}{ Ketones } \\
\hline 2-Propanone & 519.4 & 671.8 & 617.4 & 623.0 & 588.1 & 52.6 & 0.527 & 0.708 & 0.717 & B \\
\hline 2-Heptanone & 39.0 & 50.7 & 38.5 & 47.1 & 38.5 & 6.4 & 0.691 & 0.584 & 0.353 & A \\
\hline 2,3-Octanedione & 303.8 & 322.2 & 206.2 & 246.3 & 300.0 & 45.2 & 0.566 & 0.590 & 0.935 & B \\
\hline 6-Methyl-5hepten-2-one & 186.0 & 172.6 & 292.5 & 227.3 & 227.4 & 40.2 & 0.393 & 0.956 & 0.713 & B \\
\hline \multicolumn{11}{|l|}{ Nitrogen compounds } \\
\hline Pyridine & 3228.3 & 3613.7 & 3400.0 & 3120.6 & 3711.0 & 245.6 & 0.778 & 0.264 & 0.014 & B \\
\hline 2,6-Dimethyl pirazine & 388.0 & 161.6 & 229.9 & 220.0 & 298.2 & 91.0 & 0.656 & 0.698 & 0.506 & B \\
\hline \multicolumn{11}{|l|}{ Sulphur compounds } \\
\hline Carbon disulphide & 1041.0 & 1826.0 & 2392.5 & 1383.8 & 2213.1 & 638.2 & 0.635 & 0.519 & 0.206 & B \\
\hline \multicolumn{11}{|l|}{ Terpenes } \\
\hline I-limonene & 66.3 & 81.3 & 93.5 & 89.2 & 74.5 & 10.8 & 0.672 & 0.570 & 0.998 & B \\
\hline
\end{tabular}

${ }^{1}$ Reliability of identification: A, mass spectrum and RI identical with a reference compound; B, mass spectrum and RIs from literature in accordance; and C, tentative identification by mass spectrum. 
the protective effect of CLA against lipid oxidation, such as Corino et al. (2003) and Joo et al. (2002), who reported lower TBARS values in fresh pork loin and dry-cured ham from CLA-fed pigs, respectively. In addition, we have also found lower TBARs values due to dietary CLA in the same loins used in the present work, but being processed as dry-cured loin (Martin, Antequera, Muriel, Perez-Palacios, \& Ruiz, 2008b).

The antioxidant effect of CLA has been related both to a direct mechanism and to an indirect mechanism derived from the ability of dietary CLA to modify the fatty acid profile of the tissues through an increase in the proportion of SFA. According to the obtained results in the present work (Table 4), it seems that the modification of the fatty acid profile of chops due to dietary CLA was not relevant for the lipid oxidation of the samples during cooking, since despite the higher ratio SFA/unsaturated fatty acids of the chops due to dietary CLA, an impact on lipid oxidation was not observed in these chops. Therefore, it seems that dietary CLA or its combination with MUFA levels does not influence the lipid oxidation of cooked loin, neither positively nor negatively.

\subsection{Volatile profile}

The volatile compounds detected in cooked chops from pigs fed different levels of CLA and MUFA are shown in Table 5. A total of 37 compounds were detected and identified in cooked loin by HSSPME coupled to GC-MS. Identified compounds were assigned to 10 chemical families: acids ( 1 compound, $0.4 \%$ of total AU), alcohols (5 compounds, $3.3 \%$ of total $\mathrm{AU}$ ), aldehydes ( 11 compounds, $31.2 \%$ of total $\mathrm{AU}$ ), aliphatic hydrocarbons (6 compounds, $27.9 \%$ of total AU), aromatic hydrocarbons ( 5 compounds, $10.5 \%$ of total $\mathrm{AU}$ ), esters ( 1 compound, $7.2 \%$ of total $\mathrm{AU}$ ), ketones ( 4 compounds, $3.4 \%$ of total $\mathrm{AU}$ ), nitrogen compounds ( 2 compounds, $10.8 \%$ of total AU), sulphur compounds ( 1 compound, $5.2 \%$ of total $\mathrm{AU}$ ) and terpenes ( 1 compound, $0.2 \%$ of total $\mathrm{AU}$ ). No qualitative differences in the identified volatiles were found in the cooked porks. Moreover, dietary CLA, MUFA and their interaction did not affect the level of volatiles. These results would suggest that the CLA enrichment of pork or its combination with MUFA levels in pig diets would not influence the volatile profile of the cooked meat and, therefore, would not influence the volatile profile of cooked loin.

Previous studies on the effect of dietary CLA on the volatile profile of cooked pork have not been found in the scientific literature and, in general, the information concerning the effect of dietary CLA on the volatile profile of meat and meat products is quite scarce. Du et al. (2003) and Pastorelli et al. (2005) did not find differences in the volatile profile of fresh Longissimus dorsi from CLAfed pigs and in the raw meat from CLA-fed hens, respectively. However, in a different study carried out in cooked chicken meat by Du, Ahn, Nam, and Sell (2001), it was found that the content of aldehydes decreased as the dietary content of CLA increased. In the present work, despite being not significant, the levels of many aldehydes from the lipid oxidation (pentanal, hexanal, octanal, 2octenal and nonanal) of cooked pork also tend to decrease due to dietary CLA (Table 5). Since most unbranched aldehydes are derived from the lipid oxidation of unsaturated fatty acids (Frankel, 1985), the lower amount of unbranched aldehydes in cooked pork could be due to the lower proportion of their fatty acids precursors (mainly $n-9$ and $n-6$ fatty acids) on the raw meat, caused by dietary CLA, as previously reported (Martin et al., 2008e, 2008d).

We have also found a significant effect of dietary CLA on the volatile profile of the same loins from the same pigs assayed in the present work, but processed at different conditions (Martin, Antequera, Muriel, Andres, \& Ruiz, 2008a; Martin, Antequera, Muriel, Perez-Palacios, \& Ruiz, 2008c). Thus, dietary CLA affected the level of several volatile compounds of 7-day refrigerated loins, such as heptanal, 2-methyl-1-butanol, 2-methylheptane, 3-methylheptane or carbon disulphide (Martin et al., 2008a). In the case of the loins from the same pigs processed as dry-cured loin, the levels of heptanal, nonanal, 2-nonenal or 2-propanone were higher in the CLAcontaining dry-cured loins (Martin et al., 2008c). In our previous studies, with refrigerated fresh loin and dry-cured loin, we have proposed the lipid oxidation of the CLA isomers as a likely origin of heptanal and other volatile compounds, influenced by dietary CLA. In the present work, despite that the effect was not significant, the level of heptanal in cooked loin also seemed to increase for the CLA treatments, contrary to the behaviour of the rest of unbranched aldehydes. In fact, we estimated the ratio of heptanal to the rest of the unbranched aldehydes (pentanal, hexanal, octanal, 2-octenal, nonanal and decanal), and these values were 0.084 for $0 \%$ CLA, 0.089 for $1 \%$ CLA and 0.102 for $2 \%$ CLA (no significantly different). These results would support the hypothesis that a likely origin of heptanal was from the oxidation of CLA, because in general the higher the initial level of a fatty acid in a raw material, the higher the levels of the derived volatile compounds from that fatty acid in the processed meat.

Due to the origin of aldehydes from the oxidative degradation of fatty acids, the analysis of aldehydes, especially the hexanal content, has been considered as an indicator of the rate and extent of the oxidation process (Ross \& Smith, 2006). Thus, the hexanal

Table 6

Sensory analysis of cooked chops from pigs fed different levels of CLA and MUFA ( $n=5$ for each group).

\begin{tabular}{|c|c|c|c|c|c|c|c|c|c|c|}
\hline & \multicolumn{3}{|c|}{ Low MUFA } & \multicolumn{3}{|c|}{ High MUFA } & \multirow[t]{2}{*}{ SEM } & \multicolumn{3}{|l|}{$p$} \\
\hline & $0 \%$ CLA & $1 \%$ CLA & $2 \%$ CLA & $0 \%$ CLA & $1 \%$ CLA & $2 \%$ CLA & & CLA & MUFA & $\mathrm{CLA} \times \mathrm{MUFA}$ \\
\hline \multicolumn{11}{|l|}{ Appearance } \\
\hline Brightness & 3.8 & 4.5 & 4.0 & 4.0 & 4.3 & 3.9 & 0.8 & 0.263 & 0.954 & 0.752 \\
\hline \multicolumn{11}{|l|}{ Texture } \\
\hline Hardness & 5.9 & 4.3 & 4.6 & 4.7 & 4.7 & 5.4 & 1.0 & 0.199 & 0.935 & 0.064 \\
\hline Chewiness & 5.6 & 4.4 & 4.8 & 4.9 & 5.1 & 5.4 & 0.8 & 0.309 & 0.459 & 0.070 \\
\hline Juiciness & 2.9 & 3.9 & 4.0 & 3.8 & 4.0 & 3.1 & 0.8 & 0.174 & 0.982 & 0.046 \\
\hline Pastiness & 2.5 & 2.5 & 2.7 & 2.7 & 2.6 & 3.3 & 0.7 & 0.175 & 0.245 & 0.698 \\
\hline \multicolumn{11}{|l|}{ Taste } \\
\hline Saltiness & 3.5 & 3.5 & 3.7 & 3.4 & 3.6 & 3.4 & 0.3 & 0.843 & 0.464 & 0.346 \\
\hline \multicolumn{11}{|l|}{ Flavour } \\
\hline Intensity & 4.0 & 4.0 & 4.1 & 4.0 & 3.9 & 3.9 & 0.5 & 0.899 & 0.568 & 0.921 \\
\hline After-taste & 3.7 & 3.8 & 3.7 & 3.6 & 3.9 & 3.7 & 0.4 & 0.550 & 0.973 & 0.861 \\
\hline Rancid & 0.3 & 0.4 & 0.5 & 0.4 & 0.4 & 0.4 & 0.2 & 0.765 & 0.921 & 0.765 \\
\hline Umami & 3.4 & 3.5 & 3.7 & 3.5 & 3.4 & 3.4 & 0.4 & 0.773 & 0.433 & 0.702 \\
\hline
\end{tabular}


content in most cases is correlated with the results of the TBARS tests. In the present work, as was previously reported, the TBARS values of cooked chops were not influenced by the assayed treatments; this result was in agreement with the lack of effect of CLA or MUFA levels of the pig diets on the hexanal content of cooked chops. Furthermore, the lack of significant effect of dietary CLA on the volatile profile of cooked loin was in agreement with the lack of effect of CLA supplementation on the sensory analysis of cooked chops (Table 6), as it will be discussed below.

\subsection{Sensory analysis}

The supplementation of pigs with CLA did not affect the sensory characteristics of cooked pork (Table 6). In addition, this work revealed that the combination of dietary CLA with either high or low MUFA levels in pig diets was not perceived by the panellists in the sensory attributes of cooked pork. There was only a significant effect of CLA $\times$ MUFA interaction on the juiciness values of cooked pork $(p<0.05)$, but the values were not significantly different based on the Tukey's post hoc test. It seemed that a lower juiciness was perceived for chops from 0\% CLA-Low MUFA treatments, which could be related to the higher cooking losses for the chops from this treatment. A relationship between brightness and flavour intensity of cooked pork and the intramuscular fat content has been previously reported by several authors (Cameron \& Enser, 1991). In the present work, the lack of effect of the dietary treatments on the brightness and flavour intensity of cooked pork was in agreement with the lack of effect of the dietary treatments on the intramuscular fat content and volatile profile (Tables 3 and 5 , respectively).

The intramuscular fat might influenced the sensory quality of pig meat, not only through its amount, but also by its fatty acid composition. Thus, the fatty acid composition of pork meat has been related to the eating quality, as the SFA and MUFA content positively correlates with pork flavour; the PUFA content negatively correlates with pork flavour due to their higher susceptibility to oxidation (Cameron \& Enser, 1991). Within those flavour attributes, the rancidity perception in meat and meat products has been the main attribute that correlated with the oxidation of PUFA (Fernandez, Perez-Alvarez, \& Fernandez-Lopez, 1997). Due to the PUFA nature of CLA isomers, the CLA enrichment of cooked chops could lead to an increase in the lipid oxidation of CLA isomers, which in turn, could negatively influence the sensory quality. However, as previously reported, the CLA enrichment of chops did not influence the lipid oxidation or the volatile profile (Table 5) of the samples, in agreement with the lack of effect of CLA on the rancidity perception by panellist. Moreover, the modifications in the fatty acid profile due to dietary CLA did not have an effect on the sensory perception of fat characteristics, which could be partly due to the low amount of fat on the product. Therefore, it seems that dietary CLA or its combination with MUFA levels does not influence the sensory quality of cooked loin.

The available information related to the sensory attributes of CLA-enriched pork by dietary strategies is quite scarce. In general, the lack of effect of dietary CLA in the sensory attributes of cooked pork found in the present work is in agreement with the results found by Dugan et al. (1999) and by Wiegand et al. (2002), who reported that CLA supplementation to pig diets had no appreciable effects on tenderness, juiciness, or flavour intensity of cooked pork. Migdal et al. (2004) did not find significant effects of dietary CLA on most sensory attributes of cooked pork, but these authors reported an effect of dietary CLA on the flavour notes of cooked pork loin, which were mainly attributed to the modification of the fatty acid profile caused by dietary CLA. In other pork products, Corino et al. (2003) found an improvement in the melting quality in the mouth of dry-cured Parma ham from CLA-fed pigs with no other effects on the sensory qualities. Also, Larsen, Wiegand, Parrish, Franey, and Sparks (1998) did not find an effect of dietary CLA supplementation on smoked ham in terms of sensory attributes and overall acceptability.

\section{Conclusions}

The use of CLA on pig diets at different levels does not affect the cooking losses, lipid oxidation, volatile profile and sensory traits of cooked loin. Therefore, CLA could be supplemented to pig diets without affecting of the quality traits of cooked meat. In addition, dietary CLA does not show an effect upon the interaction with the MUFA levels in the diet on most quality traits of cooked pork. Therefore, the combination of dietary CLA with high MUFA diets for counteracting the increase in the ratio of SFA to unsaturated fatty acids caused by dietary CLA, could be carried out without a detrimental effect on the quality of meat and on the CLA enrichment achieved. However, regardless of the MUFA levels of the pig diets, the present work reveals that the CLA enrichment of fresh pork would decrease due to the cooking process.

\section{Acknowledgements}

This research was supported by the Ministerio de Educacion y Ciencia, Spain (AGL 2003-03538). CLA was generously provided by BASF. The valuable cooperation of Dr. Clemente Lopez-Bote and Dr. Elena Gonzalez as well as the collaboration of I+D Agropecuaria in designing the experimental diets, sampling, and pig management, are also acknowledged. Diana Martin would like to thank the Ministerio de Educacion y Ciencia for funding her research.

\section{References}

Association of Official Analytical Chemist (2000). Official methods of analysis (17th ed.). Gaithersburg, Maryland: Association of Official Analytical Chemists.

Banni, S., Angioni, E., Contini, M. S., Carta, G., Casu, V., Iengo, G. A., et al. (1998). Conjugated linoleic acid and oxidative stress. Journal of the American Oil Chemists' Society, 75, 261-267.

Cameron, N. D., \& Enser, M. B. (1991). Fatty acid composition of lipid in Longissimus dorsi muscle of Duroc and British Landrace pigs in relationship with eating quality. Meat Science, 29, 295-307.

Corino, C., Magni, S., Pastorelli, G., Rossi, R., \& Mourot, J. (2003). Effect of conjugated linoleic acid on meat quality, lipid metabolism, and sensory characteristics of dry-cured hams from heavy pigs. Journal of Animal Science, 81, 2219-2229.

Department of Health (1994). Nutritional aspects of cardiovascular disease. Report on health and social subjects no. 46. London: HMSO.

Du, M., Ahn, D. U., Nam, K. C., \& Sell, J. L. (2001). Volatile profiles and lipid oxidation of irradiated cooked chicken meat from laying hens fed diets containing conjugated linoleic acid. Poultry Science, 80, 235-241.

Du, M., Nam, K. C., Hur, S. J., Ismail, H., Kim, Y. H., \& Ahn, D. U. (2003). Quality characteristics of irradiated chicken breast rolls from broilers fed differen levels of conjugated linoleic acid. Meat Science, 63, 249-255.

Dugan, M. E. R., Aalhus, J. L., Jeremiah, L. E., Kramer, J. K. G., \& Schaefer, A. L. (1999). The effects of feeding conjugated linoleic acid on subsequent pork quality. Canadian Journal of Animal Science, 79, 45-51.

Fernandez, J., Perez-Alvarez, J., \& Fernandez-Lopez, J. (1997). Thiobarbituric acid test for monitoring lipid oxidation in meat. Food Chemistry, 59, 345-353.

Folch, J., Lees, M., \& Stanley, G. H. S. (1957). A simple method for isolation and purification of total lipids from animal tissues. Journal of Biological Chemistry, 226, 497-508.

Frankel, E. N. (1985). Chemistry of autoxidation. Mechanism, products and flavor significance. In D. B. Min \& T. H. Smouse (Eds.), Flavor chemistry of fats and oils. Champaign: American Oil Chemists' Society. p. 1.

Garcia-Esteban, M., Ansorena, D., Astiasaran, I., Martin, D., \& Ruiz, J. (2004) Comparison of simultaneous distillation extraction (SDE) and solid-phase microextraction (SPME) for the analysis of volatile compounds in dry-cured ham. Journal of the Science of Food and Agricultural, 84, 1364-1370.

Ha, Y. L., Grimm, N. K., \& Pariza, M. W. (1989). Newly recognized anticarcinogenic fatty acids: Identification and quantification in natural and processed cheeses. Journal of Agricultural and Food Chemistry, 37, 75-81.

Hur, S., Park, G., \& Joo, S. (2006). Biological activities of conjugated linoleic acid (CLA) and effects of CLA on animal products. Livestock Science, 110, 221-229.

Joo, S. T., Lee, J. I., Ha, Y. L., \& Park, G. B. (2002). Effects of dietary conjugated linoleic acid on fatty acid composition, lipid oxidation, color, and water-holding capacity of pork loin. Journal of Animal Science, 80, 108-112. 
Larsen, S. T., Wiegand, B. R., Parrish, F. C., Franey, K. J., Jr., \& Sparks, J. (1998). Sensory, color, and tenderness characteristics of processed hams from pigs supplemented with conjugated linoleic acid (2pp). ISU swine research report ASL-R1618. <http://www.extension.iastate.edu/Pages/ansci/swinereports/Meat98.html>. Accessed 10.11.07.

Maranesi, M., Bochicchio, D., Montellato, L., Zaghini, A., Pagliuca, G., \& Badiani, A. (2005). Effect of microwave cooking or broiling on selected nutrient contents, fatty acid patterns and true retention values in separable lean from lamb ribloins, with emphasis on conjugated linoleic acid. Food Chemistry, 90, 207-218.

Martin, D., Antequera, T., Gonzalez, E., Lopez-Bote, C., \& Ruiz, J. (2007). Changes in the fatty acid profile of the subcutaneous fat of swine throughout fattening as affected by dietary conjugated linoleic acid and monounsaturated fatty acids. Journal of Agricultural and Food Chemistry, 55, 10820-10826.

Martin, D., Antequera, T., Muriel, E., Andres, A. I., \& Ruiz, J. (2008a). Oxidative changes of fresh loin from pig, caused by dietary conjugated linoleic acid and monounsaturated fatty acids, during refrigerated storage. Food Chemistry, 111, 730-737.

Martin, D., Antequera, T., Muriel, E., Perez-Palacios, T., \& Ruiz, J. (2008b). Effect of dietary conjugated linoleic acid in combination with monounsaturated fatty acids on the meat composition and quality traits of dry-cured loin. Meat Science 80, 1309-1319.

Martin, D., Antequera, T., Muriel, E., Perez-Palacios, T., \& Ruiz, J. (2008c). Volatile compounds of fresh and dry-cured loin as affected by dietary conjugated linoleic acid and monounsaturated fatty acids. Meat Science. doi:10.1016 j.meatsci.2008.10.010.

Martin, D., Muriel, E., Antequera, T., Perez-Palacios, T., \& Ruiz, J. (2008d). Fatty acid composition and oxidative susceptibility of fresh loin and liver from pigs fed conjugated linoleic acid in combination with monounsaturated fatty acids. Food Chemistry, 108, 86-96.

Martin, D., Muriel, E., Gonzalez, E., Viguera, J., \& Ruiz, J. (2008e). Effect of dietary conjugated linoleic acid and monounsaturated fatty acids on productive carcass and meat quality traits of pigs. Livestock Science, 117, 155-164.

Migdal, W., Pasciak, P., Wojtysiak, D., Barowicz, T., Pieszka, M., \& Pietras, M. (2004). The effect of dietary CLA supplementation on meat and eating quality, and the histochemical profile of the $m$. longissimus dorsi from stress susceptible fatteners slaughtered at heavier weights. Meat Science, 66, 863-870.

Muriel, E., Ruiz, J., Martin, D., Petron, M. J., \& Antequera, T. (2004). Physico-chemical and sensory characteristics of dry-cured loin from different Iberian pig lines. Food Science and Technology International, 10, 117-123.

National Research Council (1998). Nutrient requirements of swine (10th ed.). Washington, DC: National Academy Press.

Pastorelli, G., Moretti, V., Macchioni, P., Lo Fiego, D., Santoro, P., Panseri, S., et al (2005). Influence of dietary conjugated linoleic acid on the fatty acid composition and volatile compounds profile of heavy pig loin muscle. Journal of the Science of Food and Agricultural, 85, 2227-2234.

Ross, C. F., \& Smith, D. M. (2006). Use of volatiles as indicators of lipid oxidation in muscle foods. Comprehensive Reviews in Food Science and Food Safety, 5, $18-25$.

Rodriguez-Alcala, L. M., \& Fontecha, J. (2007). Hot topic: Fatty acid and conjugated linoleic acid (CLA) isomer composition of commercial CLA-fortified dairy products: Evaluation after processing and storage. Journal of Dairy Science, 90, 2083-2090.

Sandler, S., \& Karo, W. (1992). Sourcebook of advanced organic laboratory preparations. San Diego: Academic Press.

Salih, A. M., Smith, D. M., Price, J. F., \& Dawson, L. E. (1987). Modified extraction 2thiobarbituric acid method for measuring lipid oxidation in poultry. Poultry Science, 66, 1483-1489.

Schmid, A., Collomb, M., Sieber, R., \& Bee, G. (2006). Conjugated linoleic acid in meat and meat products: A review. Meat Science, 73, 29-41.

Shantha, N. C., Crum, A. D., \& Decker, E. A. (1994). Evaluation of conjugated linoleic acid concentrations in cooked beef. Journal of Agricultural and Food Chemistry, 42, 1757-1760.

van den Berg, J. I. M., Cook, N. E., \& Tribble, D. L. (1995). Reinvestigation of the antioxidant properties of conjugated linoleic acid. Lipids, 30, 599-605.

Wiegand, B. R., Sparks, J. C., Parrish, F. C., Jr., \& Zimmerman, D. R. (2002). Duration of feeding conjugated linoleic acid influences growth performance, carcass traits, and meat quality of finishing barrows. Journal of Animal Science, 80, 637-643. 